\title{
Aortopulmonary collateral arteries mimicking symptomatic ductal shunting in a preterm infant
}

\author{
Jonathan R Skinner, Eric D Silove
}

\begin{abstract}
A preterm infant with bronchopulmonary dysplasia presented with clinical and Doppler echocardiographic features suggesting a left-to-right ductal shunt. The duct was ligated surgically. Clinical and echocardiographic signs did not change after ligation. Detailed colour Doppler examination ultimately showed several aortopulmonary collateral arteries giving rise to continuous turbulent flow in the main and left pulmonary arteries, similar to that seen with left-toright ductal shunting.
\end{abstract}

(Br Heart f 1995;74:93-94)

Keywords: aortopulmonary collaterals; ductal shunting

We present a case of a preterm infant with bronchopulmonary dysplasia in whom aortopulmonary collateral arteries mimicked both clinical and echocardiographic features of a left-to-right ductal shunt, leading to confusion in the diagnosis. Colour Doppler echocardiography ultimately displayed the collateral arteries clearly.

\section{Case report}

A preterm infant (31 weeks' gestation, birth weight $1305 \mathrm{~g}$ ) with bronchopulmonary dysplasia after hyaline membrane disease was transferred from a nearby neonatal unit on day 42 for ligation of the arterial duct. $\mathrm{He}$ had been born in good condition after caesarean section for transverse lie and preterm labour, and was intubated electively. $\mathrm{He}$ was ventilated for 6 days, maximal fractional inspiratory oxygen required was 0.60 , and he had two doses of surfactant. A murmur, suggestive of a patent arterial duct, was first detected on day 26. There was marked tachypnoea. Oxygen requirements via the head box increased steadily despite diuretics and steroids, from $25 \%$ to $50 \%$. The capillary carbon dioxide tension was $7.8 \mathrm{kPa}$ before transfer.

He was ventilated for transfer to our hospital, and clinical signs were consistent with a significant left-to-right ductal shunt, including a loud murmur continuing into diastole, bounding pulses, and hepatomegaly. Colour Doppler echocardiography revealed turbu- lence in the main and left pulmonary arteries continuing through diastole and apparently arising from near to the origin of the left pulmonary artery. The left atrium was only modestly enlarged, but there was continuous left-to-right flow through a wide oval foramen. The arterial duct was difficult to visualise on cross sectional echocardiography because of the hyperinflated chest, but was believed to be small but patent, mostly because of the turbulence in the main pulmonary artery. The possibility of aortopulmonary collaterals causing the echocardiographic findings was considered, but because of the clinical features it was decided to proceed to ductal ligation. At surgery, the duct was tiny, and several small aortopulmonary collateral arteries were seen to arise from the descending aorta and pass towards the pulmonary arteries.

After ligation the clinical signs were unchanged. Repeat detailed colour Doppler echocardiography showed the collaterals clearly, and the turbulence in the main pulmonary artery had not changed (figure). Respiratory failure persisted, along with hepatomegaly, wide pulse pressure, and variable heart murmur. Despite a period of continuous negative airway pressure, the baby died from respiratory failure aged four months. The parents did not agree to a postmortem examination.

\section{Discussion}

Aortopulmonary collateral arteries are common in children with cyanotic congenital heart disease but they have also been shown in babies with bronchopulmonary dysplasia during cardiac catheterisation. ${ }^{1}$ This is the first report describing colour Doppler visualisation of aortopulmonary collaterals in a preterm infant with a structurally normal heart, and the case is also unusual because the collateral arteries were associated with clinical signs of a left-to-right shunt. Collateral arteries can occur in babies with severe bronchopulmonary disease, or in babies with cyanotic heart disease, but in such babies pulmonary arterial pressure is usually high, such that left-to-right flow is of low velocity and unlikely to generate a murmur.

This report does not clarify the clinical significance of these collateral arteries. Their presence in association with bronchopulmonary dysplasia has been shown to make 

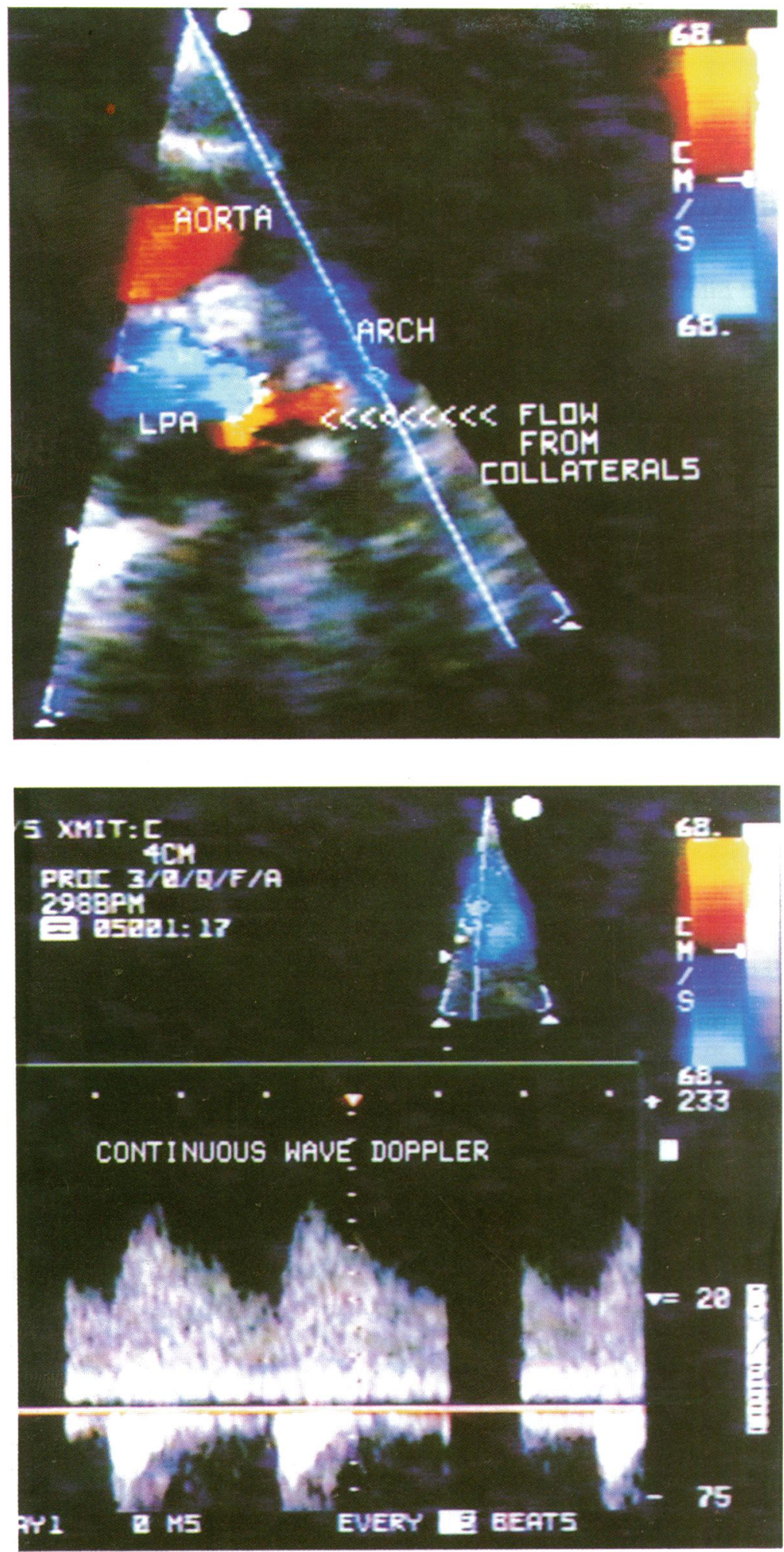

Doppler echocardiographic examination in a ventilator dependent preterm baby after ligation of the arterial duct; showing aortopulmonary collateral arteries. (A) Cross sectional echocardiogram from the high left parasternal position with colour Doppler shows left-toright flow (redlorange flare) from the distal aortic arch into left pulmonary artery (LPA). (B) Continuous wave Doppler study showing continuous flow (above the zero line) into the main pulmonary artery (peak velocity $1.6 \mathrm{~m} / \mathrm{s}$ ). the use of pulmonary vasodilators particularly dangerous, because these drugs can lead to marked systemic hypotension and hypoxaemia. ${ }^{1}$ In this case it seems that the collaterals were increasing pulmonary blood flow significantly. It is tempting to speculate that this might have a potentially harmful effect by reducing an already poor lung compliance, as occurs with left-to-right ductal shunting. In a previous report when a ventilated preterm baby underwent ligation of a major systemicpulmonary collateral artery there was a considerable improvement in respiration. ${ }^{2}$

Because clinical signs are unreliable in the detection of left-to-right ductal shunting, ${ }^{34}$ echocardiography and particularly Doppler echocardiography is relied upon increasingly to make the definitive diagnosis of a patent arterial duct. Turbulence and retrograde blood flow in the main pulmonary artery during diastole have been described as classic, even diagnostic, echocardiographic features of a left-to-right ductal shunt in this population. ${ }^{56}$ However, these features can occur with any connection between the aorta and main pulmonary artery, including surgically placed shunts and aortopulmonary collateral arteries. Clinical signs are also similar; a wide pulse pressure is typical and with a sizeable shunt there is a continuous murmur.

Clinicians therefore need to be aware that aortopulmonary collaterals do occur in bronchopulmonary dysplasia, and that they can, uncommonly present with clinical signs compatable with a left-to-right ductal shunt. Furthermore, those performing echocardiography in the preterm need to be aware that diastolic flow into the pulmonary arteries, mimicking left-to-right ductal flow, can arise from aortopulmonary collateral arteries. Particular care should be taken in babies with bronchopulmonary dysplasia to visualise the duct itself and to record flow from within it.

1 Goodman G, Perkin R, Anas N, Sperling DR, Hicks DA Rowen $M$. Pulmonary hypertension in infants with bronchopulmonary dysplasia. F Pediatr 1988;112:67-72.

2 Ascher DP, Rosen P, Null DM, Lemos RA, Wheller JJ Systemic to pulmonary collaterals mimicking ductus arteriosus in neonates with prolonged ventilatory courses. $¥$ Pediatr 1984;107:282-4.

3 McGrath RL, McGuinness GA, Way GL, Wolfe RR, Nora JJ, Simons MA. The silent ductus arteriosus. f Pediatr 1978;93:110-3.

4 Skinner JR, Hunter S, Hey EN. Cardiorespiratory collapse and the silent ductus [abstr]. Klin Pädiatr 1991;203:52.

5 Mellander M, Larsson LE, Ekstrom-Jodal B, Sabel KG. Single Doppler detection of left-to-right shunt through the ductus arteriosus. Acta Paediatr 1986;98(suppl 329):98-102.

6 Hiraishi S, Horiguchi Y, Misawa H, Oguchi K, Kadoi N, Fujino N, Yashiro K. Noninvasive Doppler echocardiographic evaluation of shunt flow dynamics of the ductus arteriosus. Circulation 1987;75:1146-53. 